\title{
Avaliação da linguagem em pacientes pós Acidente Vascular Cerebral hospitalizados
}

\section{RESUMO}

O Acidente Vascular Cerebral (AVC) tornou-se um problema de saúde pública, afetando indivíduos de diversas faixas etárias. A afasia é consequência do AVC com lesões cerebrais nas áreas responsáveis pela linguagem e, seu comprometimento varia à medida que a comunicação funcional se torna inviável. O presente estudo teve por objetivo caracterizar as alterações de linguagem em sujeitos com afasia na beira do leito hospitalar com AVC isquêmico. A amostra foi de conveniência e composta por 40 sujeitos com diagnóstico de afasia, decorrentes de AVC isquêmico com prejuízo na comunicação oral e/ou escrita, ainda em situação de beira de leito em um Hospital do interior do estado de São Paulo, por um período de 6 meses. Para a avaliação da linguagem oral e escrita foi utilizado o instrumento BEST-2 e para a avaliação da compreensão, o Token Test. As correlações entre as variáveis foram analisadas pelo coeficiente de correlação de Spearman, Mann-Whitney e Friedman. A amostra foi de sujeitos do gênero masculino (52,5\%) com idade média de 66,4 anos, com predominância do etilismo quanto aos fatores de risco (65,5\%). Quanto ao local da lesão, a distribuição foi heterogênea com fronto-parieto-temporal a direita, frontoparietal direito e tálamo esquerdo lacunar representando $10 \%$ dos sujeitos, o lado mais acometido foi o esquerdo (45\%). Do total avaliado, 97,5\% fazia uso de antitrombótico durante o período da internação. As habilidades de linguagem avaliadas estavam preservadas na maioria dos sujeitos. Os resultados apresentados demostraram nível de significância entre o teste de linguagem e a escolaridade $(p=0,02)$. Não houve diferença estatisticamente significante entre as variáveis com as habilidades de linguagens avaliadas no teste. $\mathrm{Na}$ análise do Token Test, $7 \%$ dos sujeitos apresentaram alteração de compreensão de grau leve. Como conclusão não foi possível caracterizar todas as alterações de linguagem dos sujeitos com afasia em beira de leito pós AVC, uma vez que o instrumento de rastreio BEST-2 não detectou as alterações de linguagem decorrentes de lesões do hemisfério direito.

Palavras chaves: Acidente Vascular cerebral. Afasia. Transtornos da linguagem. Testes linguagem. 